\title{
Dynamics and risk assessment of SARS-CoV-2 in urban areas: a geographical assessment on Kolkata Municipal Corporation, India
}

\author{
Suman Paul $^{1}$ (D) Subhasis Bhattacharya ${ }^{2}$ (D) Buddhadev Mandal $^{1}$ (D)

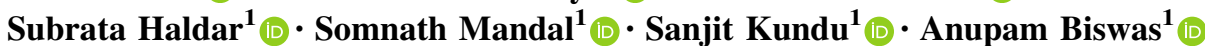

Received: 5 June 2020/Revised: 4 August 2020/Accepted: 8 August 2020/Published online: 25 August 2020

(C) Korean Spatial Information Society 2020

\begin{abstract}
SARS-CoV-2 has been transmitted and outbreak took place in India during the last week before nationwide 1st lockdown took place. Urban areas found more vulnerable and reported nearly $65 \%$ of cases during every phase of lockdown. Mumbai, among four metropolitan cities found huge number of containment zones with nearly $30 \%$ of SARS-CoV-2 cases indicating clustering of cases. Most of the containment zones of SARS-CoV-2 cases in Kolkata Municipal Corporation found a significant relation with slum areas. The study primarily tries considering the nature of SARS-CoV-2 cases in different urban centres with the help of cartographic techniques. AHP method has been
\end{abstract}

Electronic supplementary material The online version of this article (https://doi.org/10.1007/s41324-020-00354-6) contains supplementary material, which is available to authorized users.

Suman Paul

suman.krish.2007@gmail.com

Subhasis Bhattacharya

suva69eco@gmail.com

Buddhadev Mandal

buddhabm7@gmai.com

Subrata Haldar

s.haldar90@gmail.com

Somnath Mandal

mandal.somu1@gmail.com

Sanjit Kundu

sanjit.n73@gmail.com

Anupam Biswas

anupambiswas1991@gmail.com

1 Department of Geography, Sidho Kanho Birsha University, Purulia, W.B., India

2 Department of Economics, Sidho Kanho Birsha University, Purulia, W.B., India used to determine the factors responsible for such concentration of SARS-CoV-2 cases with vulnerability assessment (exposure, sensitivity and resilience) and risks. Before nationwide lockdown starts, the share of urban centres found $25 \%$ which has been transformed into nearly $60 \%$ at the end of $3^{\text {rd }}$ phase of lockdown. Growth rate of SARS-CoV-2 cases found very high for Chennai and Thane with less number of doubling time to nation. Slum concentration and containment density shows a higher degree of correlation in Kolkata Municipal Corporation. Risk map also shows the concentration of cases in central and north Kolkata with higher degree of diseases exposure and sensitivity. Control measures must be taken by the central and state Government to minimise the transmission rate of SARS-CoV-2 mainly urban areas. As urban area contributing a higher share of SARS-CoV-2 cases, a proper management plan must be enforce.

Keywords SARS-CoV-2 - Transmitted · Lockdown · AHP method $\cdot$ Slum

\section{Introduction}

In the present day context urbanisation becomes a major driver of demographic change of an area. According to United Nations report, world's population living in the urban areas has grown from 43 to 55\% during 1990 to 2015 $[1,2]$. By 2050 , it has been estimated that the world's $70 \%$ population will be reside in urban areas. This kind of urban growth and population concentration leads to sprawling and shanty development outside and within the city respectively. High population density, low per capita spacing, concentration of urban poor make significant impact on the epidemiology of the infectious diseases 
$[3,4]$. Association between urban poor and risk of pathogen transmission is very high in this scenario. High human to human propagation can easily be spike with such vulnerable condition [5]. Presently, more than 900 million populations in the world are living in slums whereas the figure of India is nearly 104 million [6]. In 1990, worldwide figure of slum populations were nearly 689 million which has been booming to 792 million in next 10 years i.e. in 2000 [7]. In the current worldwide pandemic situation of SARS-CoV-2, growth pattern, transmission nature and driving factors are the key aspects need to study.

December 31, 2019 an outbreak of COVID-19 (as known earlier) has been reported from Wuhan city of Hubei province in mainland China and rapidly spread into the other provinces of China along with 24 countries within end of January, 2020 [8]. Wuhan city has been under full lockdown (travel ban and closure of everything except essential services) from 23 January 2020 [9]. But the decision has been taken by the government was too late as the by Novel Coronavirus (nCoV-19) infections has already transmitted in different parts of mainland China and also in the different countries of the World. This episode is highly correlated with the Chinese Great Migration during the January-February when near about 415 million people are moving towards mainland China (within the Country and from outside the country) to celebrate their Lunar New Year. From mid-February countries of European continent, U.S.A, Australia facing a terrible spike of SARS-CoV-2 cases which has been not affected India at a large till the end of March, 2020. Nearly 4.9 million populations has been affected by SARS-CoV-2 and the fatality has reached into 0.32 million (as on 19-05-2020). Several countries like United States, Russia, Brazil, Italy, France, United Kingdom, Germany, Turkey, Iran has faced a major setback due the this pandemic [10,11]. India has also reached the mark of 100,000 confirmed SARS-CoV-2 cases after 64 days of first case found. Though the time taken by India to reach one lack infected cases much higher than the other countries, but the exponential triggering has been noticed during last week of $3^{\text {rd }}$ phase of nationwide lockdown (from 4 May, 2020 to 17 May, 2020). Nearly 85\% cases are reported from major cities of India and most interestingly, Mumbai, Delhi, Ahmedabad, Chennai, Thane, Pune, Kolkata become the most contributing urban centres to SARS-CoV-2 cases (as on 19 May, 2020). High population density and higher concentration of slum population make an interruption for maintaining the social distancing and lockdown effectively [12-14]. Considering such backdrop the nature of spreading of SARS-CoV-2 cases in the Indian cities need to be analysed. Further an attempt has also been made to quantify and assess the hotspot zones along with risks of the concentrated areas of Kolkata (one of the Metro city) for proper understanding of transmission of diseases in the congested and unhealthy places as a case study $[9,15,16]$.

\section{Materials and methods}

\subsection{Description of the study area}

India has only 3 cases of SARS-CoV-2 up to 3 March 2020, but all cases has transmitted and grow in a slow but steady in different areas of India especially in Urban centres. Except Kasaragode, a rural base area in Kerala, urban areas of Maharashtra, Delhi, Gujarat and Rajasthan have shown a large number of SARS-CoV-2 positive cases. In this regard, the Mumbai, Ahmedabad, Chennai, Pune, Thane, Indore, Delhi, Jaipur, Kolkata, Surat urban centres have been considered for initial analysis as these urban centres contribute more than $60 \%$ of SARS-CoV-2 cases during nationwide lockdown periods. From the analysis of urban centres contribution of SARS-CoV-2 cases, four megacities of India (i.e. Mumbai, NCR Delhi, Kolkata and Chennai) has been further chosen (Fig. 1) to find out the nature of relationship between containment zones and SARS-CoV-2 cases. As urban centres with high population density and high concentration of slum population faced a risk of rapid transmission of SARS-CoV-2, a risk analysis have also been assessed on Kolkata Municipal Corporation for the better understanding of driving factors of transmission of SARS-CoV-2.

\subsubsection{Sources of data collection}

The SARS-CoV-2 data set has been obtained from Indian Council for Medical Research (ICMR) and Health website which provide the real time data set on the outbreak of this pandemic. Another good source of data has been found from 'how India lives'. This website provides different health infrastructure dataset at district level and uploading the real time Covid-19 cases for each day at district and city level. Containment zones cities which is a very important source of information to identify the SARSCOV-2 hotspot has been taken from Health Bulletin, Govt. of West Bengal. 10 major cities of India are taken for primary level study with duration of before lockdown situation to present day (12-05-2020) scenario. The slum data set has been taken from unpublished Baseline survey report of 2016 by the Department of Bustee Services, Kolkata Municipal Corporation. As most of the dataset of Slum related indicators found from Census of India, 2011 dataset, we have to take baseline survey report of KMC. This data base has helped to identify the nature of exposure, sensitivity and resilience of world wise slam households which can assess the nature of risk among the slums. 


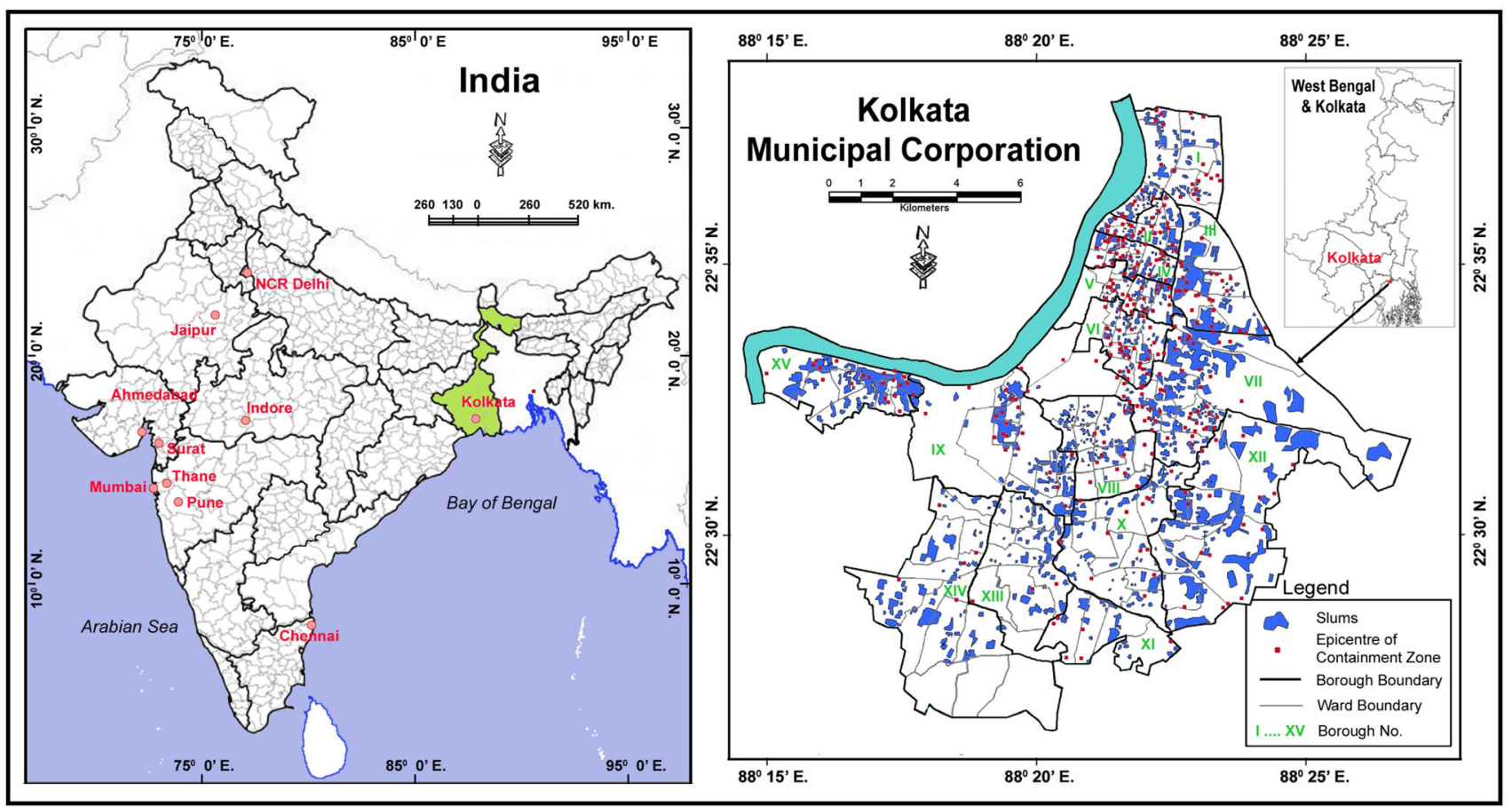

Fig. 1 Location of the urban centres in India (a) and slums with epicenter of containment zones in Kolkata Municipal Corporation (b)

\subsection{Hotspot and cluster analysis}

To depict the nature of SARS-COV-2 spatial association, local Moran's I statistic has been used to identify the cluster and spatial outlier in the neighborhood for 12-052020 dataset [16-19]. Moran's I highlights the location based cluster form high to low infection and calculated as follows:

$\mathbf{I}=\frac{Z_{i-} \bar{Z}}{V} \sum_{j-1}^{n} W_{i j} \frac{Z_{j-} Z}{V}$

where $_{Z i}$ the number of SARS-COV-2 containment zones at a spatial unit I (ward as an areal unit), $z$ is the overall containment zones in the study area (KMC as a whole) and $\mathrm{n}$ is the number of spatial unit which are 144 (No. of wards in $\mathrm{KMC}$ ) and $\mathrm{v}$ is the rate of the variance of SARS-COV-2 containment zones in different wards which is computed as below:

$\mathbf{V}=\frac{1}{n} \sum_{i=1}^{\wedge}(Z-\bar{Z})$

This method represents high (positive) and low (negative) values. High-high cluster values show the results cluster up of similar values with $\rho$-value range from 0.01 to 0.1 ( 0.1 for $90 \%, 0.05$ for $95 \%$ and 0.01 for $99 \%$ of confidence level) and Low-low cluster shows the clustering of dissimilar values with same $\rho$-values. Higher the $\rho$-values with lower the $\mathrm{z}$-score value shows the perfect significance of the method applied for study the nature of clustering pattern. The $p$ value is a value of probability. For the pattern study, it is the probability which create spatial pattern using some random process. The small p-value value suggests that the observed spatial pattern is an outcome of random process; hence null hypothesis can be rejected.

\subsection{AHP judgements}

Analytical Hierarchical Process has been developed by Satty [20] to facilitate priority setting and decision making. AHP now broadly applied in social science research and specifically in hazard and risk analysis. In this method a pairwise matrix has been developed among the set of scale of choices (Table 1) on the given alternatives [21]. AHP methods also deliver to judge the nature of consistency of preferences given by the report using consistency ratio when the value has $0.10(\mathrm{CR} \geq 0.10)$. The consistency ratio is defined as:

\section{$\mathbf{C R}=\mathbf{C I} / \mathbf{R I}$}

where CR is consistency ratio, RI represent random number (table) and CI represent consistency ratio is expressed by

$\mathbf{C I}=(\lambda \mathbf{m a x}-\mathbf{n}) /(\mathbf{n}-\mathbf{1})$

For the present work, consistency ratio has been found as 0.07 , consistency index as 0.04 and the value of random number for $\mathrm{n}=3$ has been determined 0.58 . 
Table 1 Explanations of components and indicators for risk assessment of SARs-Co-V-2

\begin{tabular}{|c|c|c|c|c|c|c|}
\hline \multirow[t]{2}{*}{ Components } & \multirow[t]{2}{*}{ Indicators } & \multicolumn{5}{|l|}{ Risk factor } \\
\hline & & 1 & 2 & 3 & 4 & 5 \\
\hline \multirow[t]{5}{*}{ Exposure } & $\begin{array}{l}\text { No. of SARS-CoV-2 containment zones/'0000 } \\
\text { population }\left(\mathrm{E}_{1}\right)\end{array}$ & Below 0.5 & $0.5-1.00$ & $1.01-1.50$ & $1.51-2.00$ & Above 2.0 \\
\hline & $\begin{array}{l}\text { Percentage share of slum population to total } \\
\text { Ward population }\left(E_{2}\right)\end{array}$ & Below 15 & $15.0-30.0$ & $30.1-45.0$ & $45.1-60.0$ & Above 60.0 \\
\hline & No. of containment zones/sq. km. $\left(\mathrm{E}_{3}\right)$ & Below 4.0 & $4.0-8.0$ & $8.01-12.0$ & $12.01-16.0$ & Above 16.0 \\
\hline & No. of slums located in the ward $\left(\mathrm{E}_{4}\right)$ & Below 15 & $15-30$ & $31-45$ & $46-60$ & Above 60 \\
\hline & $\%$ of Area under slums to total ward area $\left(\mathrm{E}_{5}\right)$ & Below 20 & $20.0-40.0$ & $40.1-60.0$ & $60.1-80.0$ & Above 80.0 \\
\hline \multirow[t]{6}{*}{ Sensitivity } & HHs size $\left(\mathrm{S}_{1}\right)$ & Below 4.0 & $4.0-4.5$ & $4.51-5.0$ & $5.01-5.50$ & Above 5.0 \\
\hline & $\%$ of $\mathrm{HHs}$ size with 5 persons and more $\left(\mathrm{S}_{2}\right)$ & Below 30.0 & $30.0-40.0$ & $40.1-50.0$ & $50.1-60.0$ & Above 60.0 \\
\hline & No. of persons/latrine used $\left(\mathrm{S}_{3}\right)$ & Below 10 & $10-20$ & $21-30$ & $31-40$ & Above 40 \\
\hline & No. persons/tube well used $\left(\mathrm{S}_{4}\right)$ & Below 200 & $200-400$ & $401-600$ & $601-800$ & Above 800 \\
\hline & Population density $\left(\mathrm{S}_{5}\right)$ & Below $20 \mathrm{k}$ & $20-40 \mathrm{k}$ & $40.1-60 \mathrm{k}$ & $60.1-80 \mathrm{k}$ & Above $80 \mathrm{k}$ \\
\hline & Household density $\left(\mathrm{S}_{6}\right)$ & Below $5 \mathrm{k}$ & $5-10 \mathrm{k}$ & $10.1-15 \mathrm{k}$ & $15.1-20 \mathrm{k}$ & Above $20 \mathrm{k}$ \\
\hline \multirow[t]{5}{*}{ Resilience } & Drinking water facility within premise $\left(\mathrm{R}_{1}\right)$ & Above 85.0 & $75.1-85.0$ & $65.1-75.0$ & $55.0-65.0$ & Below 55.0 \\
\hline & $\begin{array}{l}\text { HHs access to drinking water from treated } \\
\text { source }\left(\mathrm{R}_{2}\right)\end{array}$ & Above 97.5 & $95.01-97.5$ & $92.51-95.0$ & $90.0-92.5$ & Below 90.0 \\
\hline & $\%$ of literate person $\left(\mathrm{R}_{3}\right)$ & Above 80.0 & $70.1-80.0$ & $60.1-70.0$ & $50.0-60.0$ & Below 50.0 \\
\hline & $\begin{array}{l}\text { Average per-capita income of the slums } \\
\text { located in the ward }\left(\mathrm{R}_{4}\right)\end{array}$ & Above $4.00 \mathrm{k}$ & $3.51-4.00 \mathrm{k}$ & $3.01-3.50 \mathrm{k}$ & $2.50-3.00 \mathrm{k}$ & Below $2.50 \mathrm{k}$ \\
\hline & Work participation rate $\left(\mathrm{R}_{5}\right)$ & Above 40.0 & $35.1-40.0$ & $30.1-35.0$ & $25.0-30.0$ & Below 25.0 \\
\hline
\end{tabular}

Source: Computed by the authors

\subsubsection{Assessment of risk}

Based on socio-economic data of slum of Kolkata Municipal Corporation and containment zone data and containment zone data from different web sources we have selected the following indicators for quantity exposure, sensitivity and resilience for assessing the risk [22] infector disease like SARS-CoV-2 (see Table 1).

\subsubsection{Exposure indicator}

The study considered the following as exposure indicators, number of SARS-CoV-2 containment zones/'0000 population $\left(E_{1}\right)$, percentage share of slum population to total world population $\left(\mathrm{E}_{2}\right)$, number of containment zones sq.km $\left(E_{3}\right)$, number of slum located in the ward $\left(E_{4}\right)$, and percentage slum area to total area of the ward $\left(\mathrm{E}_{5}\right)$.

\subsubsection{Sensitivity indicators}

The study considered the following as sensitivity indicators, HHs size $\left(\mathrm{S}_{1}\right)$, percentage of HHs size with 5 persons and above $\left(\mathrm{S}_{2}\right)$, no. of persons in the slum, used community toilet, no. of persons/tube well used $\left(\mathrm{S}_{3}\right)$, population density $\left(\mathrm{S}_{4}\right)$ and household density $\left(\mathrm{S}_{5}\right)$.

\subsubsection{Resilience indicators}

The study considered the following as resilience indicators, percentage of HHs access to drinking water facility within premise $\left(\mathrm{R}_{1}\right)$, percentage of $\mathrm{HHs}$ access drinking water from treated source $\left(R_{2}\right)$, percentage of literate population $\left(R_{3}\right)$, average per capita income of the slum located in the ward $\left(\mathrm{R}_{4}\right)$ and work participation rate $\left(\mathrm{R}_{5}\right)$.

Number of containment zones/'0000 population in one of the most important indicators affecting the exposure of SARs-COV-2 cases. According to ICMR, the SARS-CoV2 cases are taken the epicenter of this containment zone [23]. On the basis of data, we have divided the whole data set into 5 categories having high risk factor to low risk factor (above 2.0/'0000 population, $1.51-2.0 / 20000 \mathrm{popu}-$ lation $1.0-1.5 /{ }^{\prime} 0000$ population, $0.5-1.0 /{ }^{\prime} 0000$ population and below $0.5 /{ }^{\prime} 0000$ population).

Share of slum population is another prime indicator to explain the exposure of such infections dieses $\mathrm{H} 2 \mathrm{H}$ pattern. So the shanty and confected household are very much exposed to such dieses. Here, we also divide the whole set of data into 5 categories on the basis of risk factor. Density of containment zones in another good indicator for assessing the nature of exposure. As the density is increasing, the exposure of SARs-COV-2 to other persons 
becomes very high. Slum area to total area is another crucial factor as areal coverage increase, the congestion pattern of living, unhygienic situation are very much exposed. Thus higher the percentage signifies higher risk factor. Each of the indicators has been categories under five classes of risk factor and weightage of these indicators have been assigned using AHP method. The exposure index of SAR-COV-12 has been determined using following formula.

\section{Exposure Index $(\boldsymbol{E I})$ :}

$$
=\boldsymbol{\Sigma}\left(\mathbf{E}_{1 \mathrm{c}} \cdot \mathbf{E}_{\mathbf{1 w}}\right)+\boldsymbol{\Sigma}\left(\mathbf{E}_{\mathbf{2 c}} \cdot \mathbf{E}_{\mathbf{2 w}}\right) \ldots \ldots \ldots \ldots \boldsymbol{\Sigma}\left(\mathbf{E}_{\mathbf{n c}} \cdot \mathbf{E}_{\mathbf{n w}}\right)
$$

where $E_{1 c}$ denote the ward data lies or which class [class 1-5] as mentioned in Table 2 and $E_{1 w}$ is weightage assessed using AHP model.

Here, in this study purpose identifies the factors which can trigger the intensity and probability of spiking up of SARS-COV-12 cases. Household size undoubtedly increases the extent of severity of such $\mathrm{H} 2 \mathrm{H}$ infectious disease. Population belonging in a household also led the situation more badly. When social distancing is addressed nationwide, the poor people of the slums cannot maintain such as due to shortage of space in the households. Community toilet and tube well use is also promoting the chances of mass gathering in the slams. Many people are living under such shanty places and also depend upon these facilities which can aggravate and spread such infectious disease in the community level. Sensitivity index can be expressed in the following manner:

Sensitivity Index $(S I)$ :

$$
=\boldsymbol{\Sigma}\left(\mathbf{S}_{1 \mathrm{c}} \cdot \mathbf{S}_{\mathbf{1 w}}\right)+\boldsymbol{\Sigma}\left(\mathbf{S}_{2 \mathrm{c}} \cdot \mathbf{S}_{\mathbf{2 w}}\right) \ldots \ldots \ldots \ldots\left(\mathbf{S}_{\mathrm{nc}} \cdot \mathbf{S}_{\mathrm{nw}}\right)
$$

where $S_{1 c}$ denote the ward data lies or which class [class $1-5]$ and $\mathrm{S}_{1 w}$ is weightage assessed using AHP model.

Resilience can be defined as reduction and prevention approach to risk any vulnerability for making an area more socio-economically stronghold [24]. Drinking water facility with premises and from treated source, level of literate population are the important indicators for resilience study. On the other hand per capita income and work participation rate is the potential indicator to increase the resilience of the any households. Resilience index can be determined as:

\section{Resilience Index $(\boldsymbol{R I})$ :}

$$
=\boldsymbol{\Sigma}\left(\mathbf{R}_{\mathbf{1 c}} \cdot \mathbf{R}_{\mathbf{1 w}}\right)+\boldsymbol{\Sigma}\left(\mathbf{R}_{\mathbf{2 c}} \cdot \mathbf{R}_{\mathbf{2 w}}\right) \ldots \ldots \ldots \ldots \boldsymbol{\Sigma}\left(\mathbf{R}_{\mathrm{nc}} \cdot \mathbf{R}_{\mathrm{nw}}\right)
$$

where $\mathrm{R}_{1 c}$ denote the ward data lies or which class [class 1-5] and $\mathrm{R}_{1 w}$ is weightage assessed using AHP model.

On the basis of assessed results from exposure index (EI), sensitivity index (SI) and resilience index (RI), risk of the selected wards have been estimated using following methodology as prescribed by IPCC [22] framework:

$\operatorname{Risk}(\mathrm{R}):\left(\mathrm{EI}_{w}, w_{e}+\mathrm{SI}_{w}, w_{s}+\mathrm{RI}_{w}, w_{r}\right)$

where $E I_{w}$ is the exposure index, $w_{e}$ weightage of exposure, $S I_{w}$ is the sensitivity index, $w_{s}$ weightage of sensitivity, $R I_{w}$ is the resilience index, $w_{r}$ weightage of resilience.

\section{Results and discussion}

\subsection{Transmission trajectory of SARS-CoV-2 in the prime urban centres}

Outbreak of novel Corona virus (earlier it is termed as 2019-nCov and later renamed as SARS-CoV-2 during the preparation of this manuscript) leading to lockdown (which means entire closure of all services except frontline services and essential services, i.e., banking, fire service etc.) of entire Country which took place on and from 24th April, 2020 midnight. Till date of the preparation of this manuscript, India already gone through three phases of lockdown (which will end on 17th May, 2020) and during these phases, urban centres have been found the most threating situation contributing nearly $60 \%$ of total affected cases of SARS-CoV-2 from 10 most popular cities of India. Nearly $75 \%$ of cases and deaths reported as far, lies with the Country's 35 most popular urban agglomeration and twothird cases and deaths are just 10 of those 35 UA's. These 35 UA's are spreading over the 16 States and NCR Delhi [25]. India has shown a clear demarcation of SARS-CoV-2 cases in geographical spatiality of rural and urban areas. But presently, returning back of migrant workers to their native rural land may transmit and spreading the cases over the rural belt of India also.
Table 2 AHP pairwise matrix, weightage and consistency measurement of components for risk assessment of SARs-Co-V2

\begin{tabular}{llllllll}
\hline Components & Exposure & Sensitivity & Resilience & $\mathrm{C}_{\mathrm{p}}$ & $\lambda \max$ & $\mathrm{CI}$ & $\mathrm{CR}$ \\
\hline Exposure & 1.00 & 3.00 & 3.00 & 0.56 & & & \\
Sensitivity & 0.33 & 1.00 & 3.00 & 0.29 & 3.08 & 0.04 & 0.07 \\
Resilience & 0.33 & 0.14 & 1.00 & 0.15 & & & \\
Sum & 1.66 & 4.14 & 7.00 & 1.00 & & & \\
\hline
\end{tabular}

Source: Computed by the authors using AHP 


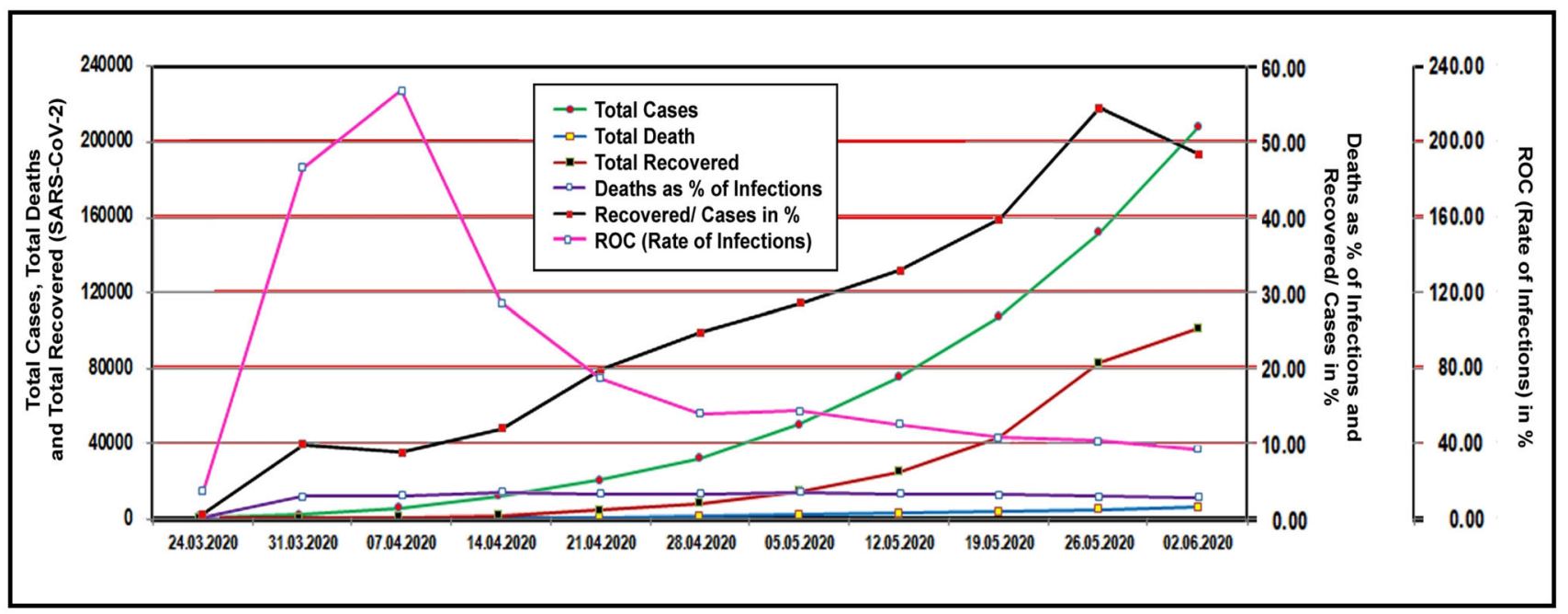

Fig. 2 Growth of SARS-CoV-2 confirmed cases along with deaths and recoveries in India during 24-03-2020 to 02-06-2020

It was May 6, 2020 when India experienced 52,469 confirmed SARS-CoV-2 cases with 1771 death and entered into the list of top fifteen countries of the world. It is only $1.41 \%$ SARS-CoV-2 cases to rest of the world but it was only $0.13 \%$ (536 cases) when nationwide lockdown started. The surge of SARS-CoV-2 cases as seen by USA, Italy, France, Germany, Brazil, Russia was not same in India till 19 May, 2020. Cases are found to be doubled in every 11 days at that time. But after 20 May, 2020 a large spike has been found till 2 June, 2020 which put India in the same bracket as Brazil and Russia in terms of upward trend in the infected cases and fatalities. The fact that despite of four lockdown imposed by Central and State governments combine, the stringent index has been found to fall from 100 (on 24-03-2020) to 79.2 (26-05-2020) which make a straightway relation of surging the SARS-CoV-2 cases in the different parts of India (Fig. 2). Another issue is the return back of stranded labour from mainly southern and western States to the eastern portion make this spread to rural areas also.

Based on the dataset and Fig. 3 of SARS-CoV-2 of 10 major urban centres, Mumbai has been found most cases with one-fifth (19.35\%) to total Country's cases up to 12th May, 2020 when the lockdown starts on 24th March, 2020 it was only $6.65 \%$ of whole Country with a rapid growth of $1.183,1.085$ and 1.049 during 1 st phase, 2 nd phase and 3rd phase of lockdown respectively. Doubling rate of cases is 1.2 times (Mumbai doubled the cases in 11.5 days as on 12.05.2020) to Country doubling time (9.7 days). NCR Delhi also contributes a larger extent of SARS-CoV-2 cases with $9.78 \%$ which was only $5.25 \%$ just before lockdown. A single event at Nizamuddin Marcus (a religions congregation) makes the situation worse during first phase of lockdown [26]. A sharp rise or cases (nearly
$13.59 \%$ to Country's total cases) has been experienced during this time which has been slow down gradually. Stringent actions have been taken by the respective state governments which reflect in the higher rate of doubling time (11.8 days) to Country's data. After NCR Delhi, Ahmedabad from state of Gujarat originate as a big area of concern for the Country which contributing $8.22 \%$ of total Country's cases at the end lapse of 3rd phase of lockdown but it was only $2.45 \%$ at the starting of 1 st phase of lockdown. During 2nd phase of lockdown a tremendous spike in the cases of SARS-CoV-2 has been experienced by this urban centre. During these phase, most of the cases (nearly 70\%) are related to travel within the Country and related to Delhi's religious congregation took place is end of March, 2020 [27]. Through having higher value of doubling rate (11.4 days to double) from Country's perspective and having decreasing growth rate. Number of containment zones gives a clear picture of clustering of cases which signifies the nature of community spreading which is a matter of uneasiness.

Chennai shows an alarming situation with $5.43 \%$ of cases during the end period of 3rd phase of lockdown which was just $1.05 \%$ on 24.03 .2020 (just before the lockdown). Though the growth rate is decreasing (from $1.17 \%$ at 1 st phase of the lockdown and $1.108 \%$ at nearly end of 3rd phase of lockdown) but the doubling time of cases is 6.25 days which signifies a great risk. Among all the 10 urban centres under study (which are combine contribute 56:28\% of cases), Chennai has the lowest doubling time which is a matter of concern. On 14th May 2020, nearly 2600 SARS-CoV-2 have been outlined to a wholesale vegetable market named Koyambedu and authorities have acknowledged it as a coronavirus hotspot [28]. After cases being reported from the popular market of 


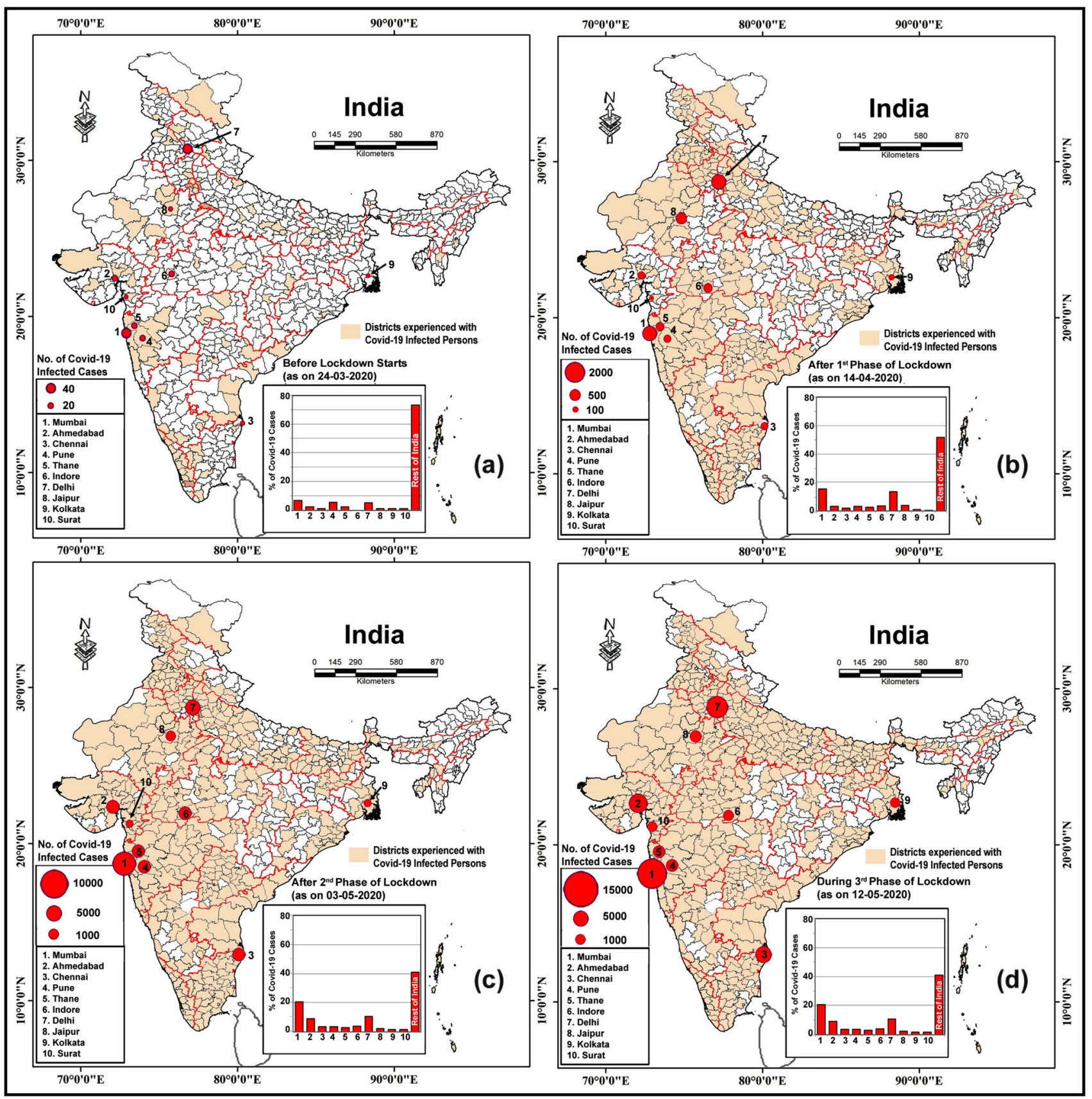

Fig. 3 Growth and share of SARS-CoV-2 confirmed cases among the prime cities in India during different period of time (a) before lockdown starts; (b) after 1st phase of lockdown; (c) after 2nd phase of lockdown and (d) during 3rd phase of lockdown

Chennai (500 cases in last $24 \mathrm{~h}$ ), state of Tamilnadu has surpassed the figures of Delhi and it is the third-worst SARS-CoV-2 state in India [29].

On the other hand Kolkata shows a steady but consistency in growth and spreading of SARS-CoV-2 cases. Almost in all the lockdown phases, Kolkata shows much below transmission of SARS-CoV-2 and contributing least to Country's tota. Doubling rate gives a clear picture of this scenario with almost 12.2 days which is a good indication with a population of nearly 4.5 million and having nearly $26.17 \%$ of slum population lived in this region (Census, 2011).

Pune (3.34\%), Thane (3.19\%), Indore (2.63\%), Jaipur $(1.70 \%)$ and Surat $(1.26 \%)$ contribute nearly $12.06 \%$ of the cases to Country's total. Growth rates of SARS-CoV-2 in these urban centres are constantly decreasing which is a good pictogram of action taken by the Government of those states as well as social awareness with following social 
distancing. Among all the urban centres, Thane shows an alarming situation in doubling rate which is 6.9 days and thus Thane can be an emerging hot spot like Mumbai and Chennai if proper action not taken at the earliest.

\subsection{Containment zones and SARS-CoV-2 cases among the four metro cities of India}

Two days before the second phase of lockdown started, India has charted identification of Red, Orange and Green zones which is a strategic approach for defining the area of operation, applying perimeter control, delineating containment and buffer zones. Meanwhile Ministry of Health and Family Welfare, Govt. of India declared 170 districts as 'hotspots' and 207 districts as 'non-hotspots'. Ministry also categorises hotspots in two way-(a) Clusters-increase in the incidence of SARS-CoV-2 with less than 15 cases and there must be epidemiologically linked and (b) Large outbreak-when more than 15 cases have been found from a defined geographical area and these cases may not be epidemiologically linked. To combat with this pandemic, State Governments have begun to experiment the idea of containment zones to deal with SARS-CoV-2. Mechanism of the containment zones is very straight forward, clusters or large outbreak which shown rise of cases and shown rapid transmission either in family or in community must be seated. Movement in these zones are very limited which is only for foot line workers and residential movement is completely ban. When large number of cases are found in a smaller number of containment area it may a reflection of large outbreak (ratio is very high) but when large amount of cases with larger number of containment area (the ratio is low) suggest the clustering of disease took place.

In case of comparison of confirmed new cases on daily data initiated from the period of first lockdown for four cities is smoothen using five year weighted moving average method. The study considers the weights as defined by using the rule

$w_{i}=\frac{1}{\sum_{i=1}^{5} x_{i} / 5}=\frac{5}{\sum_{i=1}^{5} x_{i}}$

The weighted value of moving average can be calculated from $\sum_{i=1}^{5} x_{i} w_{i}$ for the corresponding five values of the series. The study deals with the three types of lock down considering them as Phase-I (consist of 21 days starting from 25.03.2020), Phase-II (consist of 19 days starting from 15.04.2020), and the Phase-III (consist of 9 days starting from 04.05.2020). The smoothing data set of new cases of nCovid-19 syndrome is depicted in Fig. 4.

The nature of the new cases shows that situation of Kolkata is relatively best in compare to other three cities
[30]. Whatever be the ways the explosion of new cases are found with some controlled behaviour and even with rare fluctuations. The situations of Chennai showing some controlled behaviour up to 27.04.2020 i.e. in the middle of Phase-III lockdown but as the relaxation in the lockdown started the outbreak increases with huge rate. Similar path also observable for Delhi NCR like Chennai, but it includes massive fluctuations. As time precedes the frequencies of fluctuations in case of Delhi also increases. The situation of Mumbai is worse among the all four cities. The periodic up and downs of the new cases puzzle the governance to control it. The linear trend line for cities shows that the line is steepest for Mumbai, and it is more than double of Delhi.

Four metro cities shows different pattern of transmission during end ward of 1st phase of lockdown to present time. Delhi shows a higher ratio between number of SARS-CoV2 cases and containment zones suggesting the larger outbreak for the region. On the other hand Mumbai, Chennai and Kolkata show a clustering scenario of these cases during this time setting. Higher number of cases with lower ratio also suggests the expansion of the SARS-CoV-2 cases in the new areas in faster rate. In 12 May 2020, Mumbai and Chennai show nearly same value (6.46 and 6.54 respectively) but with the SARS-CoV-2 cases nearly 3.5 times to Chennai. Mumbai city shows a huge spreading along different places in this period of time. During this period, Delhi shows a much higher rate fluctuating from 35.63 to 42.47 (having a highest ratio of 72.05 ) and pinpointing the large out break as stated earlier. During this period, Kolkata shows a steady pattern having a ratio of 1.9-2.64.

The containment zones caused trouble to the citizens, by restricting the mobility almost entirely and have to depend on government officials and selected venders for maintaining the essential services. This methodology of curtailment of rights is temporary for the containing and stops the spreading of disease. But slums in the urban area cannot fully follow the thumb rules of such containment zone. As these people lives in a shanty, unhygienic environment, and using community toilet with large dependency on tube well for water accessibility are very much susceptible for these $\mathrm{H} 2 \mathrm{H}$ transmission. Mumbai and Delhi shows the perfect example of such transmission. Dharavi, the world famous slum has been hardly heated by this pandemic. Kolkata face a challenge to combat with the spreading of SARS-CoV-2 cases in the densely slums concentrated areas [7]. Most of the wards in KMC having more than 10 containment zones where a large percentage of population living in the slums. Increasing number containment zones along with number of cases has proven the spatial dispersal of SARS-CoV-2 cases in KMC which is needed to be studied further. 


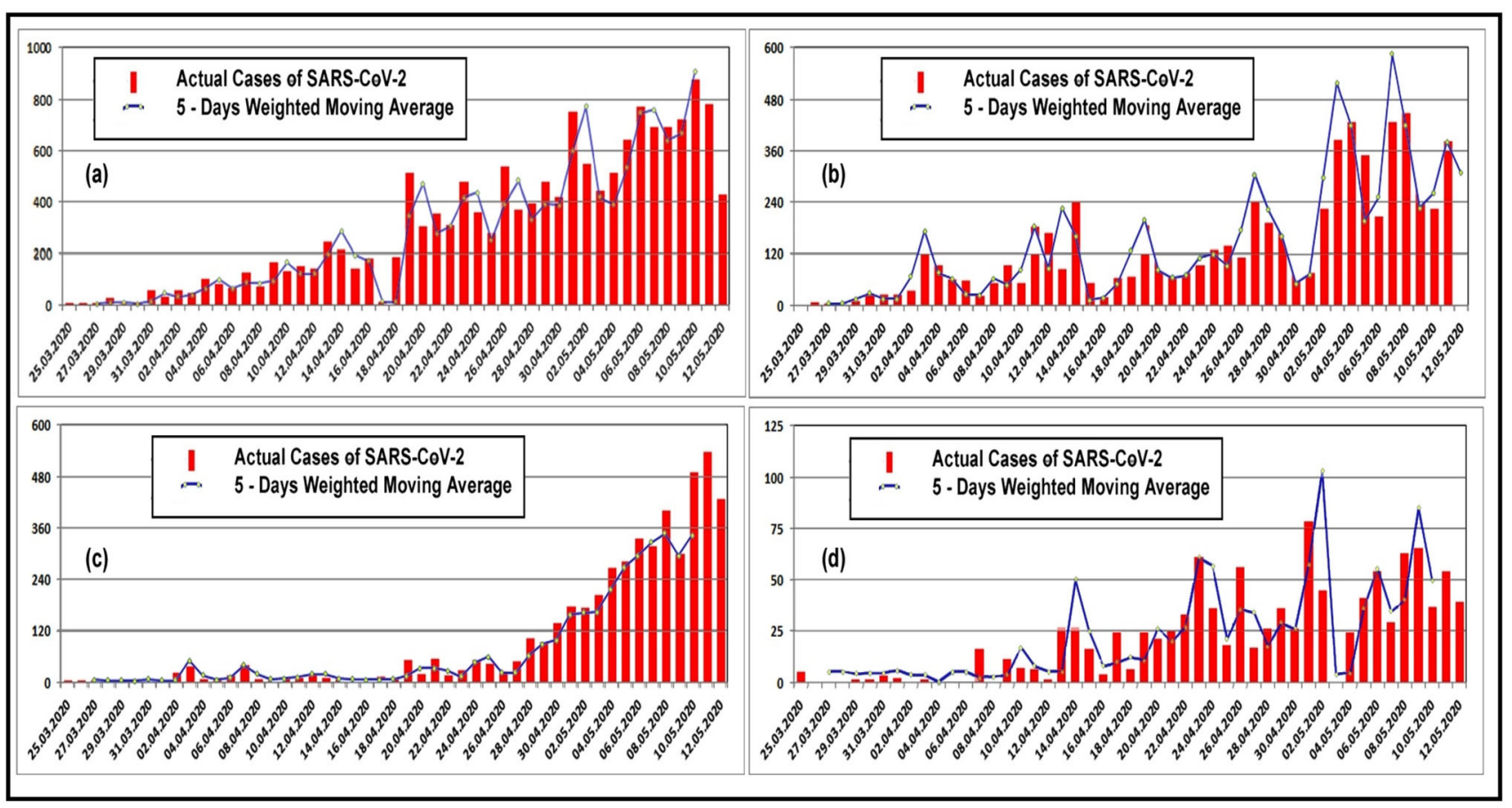

Fig. 4 Growth of SARS-CoV-2 confirmed cases with 5-days weighted moving for Mumbai (a), NCR Delhi (b), Chennai (c) and Kolkata (d) during 24 March 2020-12 May 2020

\subsection{Hot spot and clustering of SARS-CoV-2 in Kolkata Municipal Corporation}

Figure 5 shows the time series pattern of the confirmed cases of SARS-CoV-2 from 1st case detected on 17th March, 2020 to 12th May, 2020 when cumulative number were 1068 and 2173 for KMC and State of West Bengal respectively. As Kolkata has experienced 1st case of SARS-CoV-2, here we have taken ward wise containment zone to find out the nature of hot spots located in the Municipal area. As per ICMR, containment zone confirms the epicentre of cases and due to unavailability of SARSCoV-2 ward wise data; we used number of containment zones as proxy indicator [23]. Figure 5 also confirms that, up to 1st week of April 2020 Kolkata Municipal Corporation (CMC) contributes a huge percentage share to State's total which has been decreasing afterwards. This scenario again found from starting of fourth week of April when Kolkata share nearly $70 \%$ of State's total. A huge population of nearly 45 lakh (Census of India, 2011) with a high percentage share of slum population $(31.35 \%)$ is very much vulnerable for transmitting this $\mathrm{H} 2 \mathrm{H}$ virus where population density, slum density, using per capita community latrine and tube well are high [31].

Figure 6 shows the hot spots for Covid-19 using SaTScan on the basis of two different dates dataset on containment zones result which identifies two primary clusters and three secondary clusters with high confidence value (p-values are found less than 0.01) in KMC. The primary clusters are located covering (a) Kareya, Tiljala, Topsia, Tansra, Survey park region and (b) Jorabagan, Burtola, Girish Park area. Secondary clusters have been identified to designate more cases likely to aggregate from KMC which are extent from Northern portion to SouthWestern portion. These secondary clusters have also the significance values less than 0.05 (p-value). The highly decentralized nature of incidence of this disease clearly showed limited hotspots within the city of Kolkata. Ward no. 66 (Tiljala/Topsia area) has been found a large number of containment zones in a smaller area and it has increasing very sharp. This area has fallen the primary cluster of Central Kolkata when ward no. 18 and 26 (Banstala, Girish Park region) are fallen under another primary cluster.

The SARS-CoV-2 views caused tremendous pressure situation in the 97 wards in Kolkata Municipal Corporation out of 144 wards (Fig. 7a). 227 containment zones have been found on those 97 wards on 27-04-2020 which has been increased into 338 numbers located in 124 wards. The distribution pattern of containment zones in two different dates has shown a clear increase in spatiality among the wards of KMC. The highest number of zones has been found in the wards located in Central Kolkata, East suburban and port area and some portion of north Kolkata. Huge numbers of slums (registered and unregistered) are found in those areas which may play a role of catalyst to spread and transmitted this pandemic [32]. Highest 


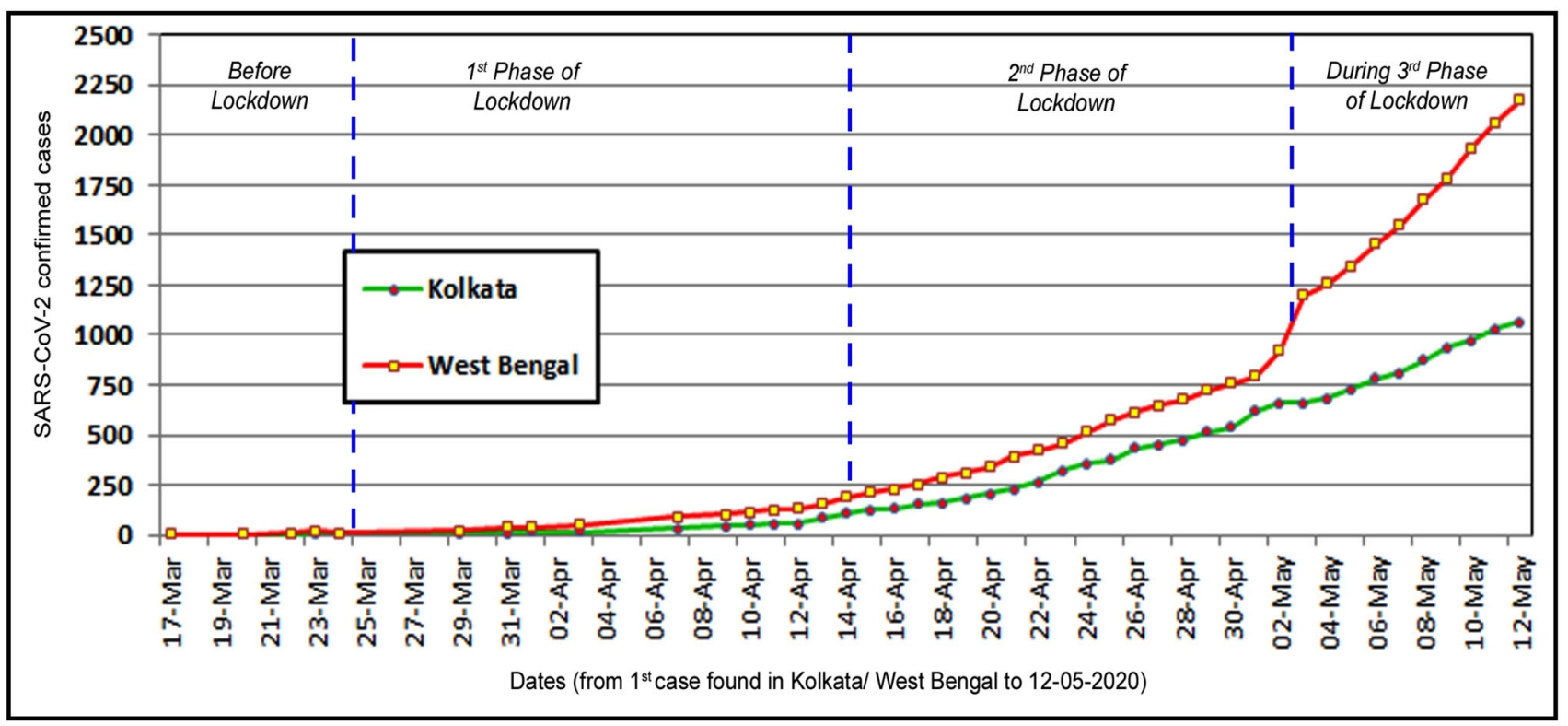

Fig. 5 Growth of SARS-CoV-2 confirmed cases in Kolkata Municipal Corporation and State of West Bengal during 17 March 2020-12 May 2020

concentrations of containment zones have been found in Tiljala, Kareya, Beliaghata, Phoolbgan, Razabazar, Tala, Burtola, Jorabagan, Girish Park, Bowbazar, Entally, Muchipara, and Survey Park area. Total number of containment zones in this area have been covered nearly $50 \%$ of the total containment zones (Fig. 7b).

Wards with high containment zones are falling in those wards which have a higher degree of slum population as well as the number. Most of the areas under slums are very old and developed before Independence [31]. Old shanty dwelling slots with higher family size, higher dependency on community toilet/latrine with water availability source as tube well make the area more risky and vulnerable to this SARS-CoV-2 [33]. As it is already known to everyone that this infection can transmit $\mathrm{H} 2 \mathrm{H}$ pattern and Ro of 2.5 , it is really need to assess the scenario of those slums for better approach to stop the transmission and break the chain of this infection. Here need the assessment of the risk of those hotspot areas to make a proper evaluation of vulnerability and steps to be taken in coming days.

\subsection{Risk assessment of SARS-CoV-2 in Kolkata Municipal Corporation (KMC)}

\subsubsection{Containment zone and risk assessment}

Here we used the dataset provided by Health Bulletin, Govt. of West Bengal from which hotspots and cluster analyses have been done. On the basis of hotspots and cluster analyses we have found the Gi-Zscore values which are lies from ' +5.4 ' to ' -3.4 '. Higher positive values show the wards (areal unit of study) with higher degree of (having $\rho$-values within $0.01-0.1$ ) with higher degree of containment zones. For the risk assessment of such $\mathrm{H} 2 \mathrm{H}$ infectious disease, we have selected only 68 wards out of 144 wards located under Kolkata Municipal Corporation. Two primary clusters and three secondary clusters are falling in this study area. On the basis socio-economic dataset provided by Bustee Cell, KMC and Census of India, 2011; exposure, sensitivity and resilience (on selected wards) have been evaluated. With the help of these findings, risk to $S A R S-C o V-2$ has been determined using the following formula:

$\operatorname{Risk} \operatorname{Index}(\boldsymbol{R I})=\mathbf{E w} \cdot \mathbf{E i}_{\mathbf{w}}+\mathbf{S w} \cdot \mathbf{S i}_{\mathbf{w}}+\mathbf{R w} \cdot \mathbf{R i}_{\mathbf{w}}$

where $\mathrm{Ew}$ is weightage of exposure, $\mathrm{Ei}_{\mathrm{w}}$ is the ward-wise exposure index, $\mathrm{Sw}$ is weightage of sensitivity, $\mathrm{Si}_{\mathrm{w}}$ is the ward-wise sensitivity index, $\mathrm{Rw}$ is weightage of resilience and $\mathrm{Ri}_{\mathrm{w}}$ is the ward-wise resilience index.

On the resulted dataset, risk zones have been categorised into 5 classes from very high risk zone to very low risk zone. Of the total selected wards under study (68), 6 are very highly exposed to $S A R S-C o V-2$ followed by highly exposed wards (16), moderately exposed (22), low exposed (11) and very low exposed (9) categories. The exposure index is composed of SARS-CoV-2 containment zones density with population, share of slum population and density of slums with areal coverage to ward area made the wards located in north and central Kolkata more exposed as these areas are very old and the slums in these wards have an age of more than 75 years. 


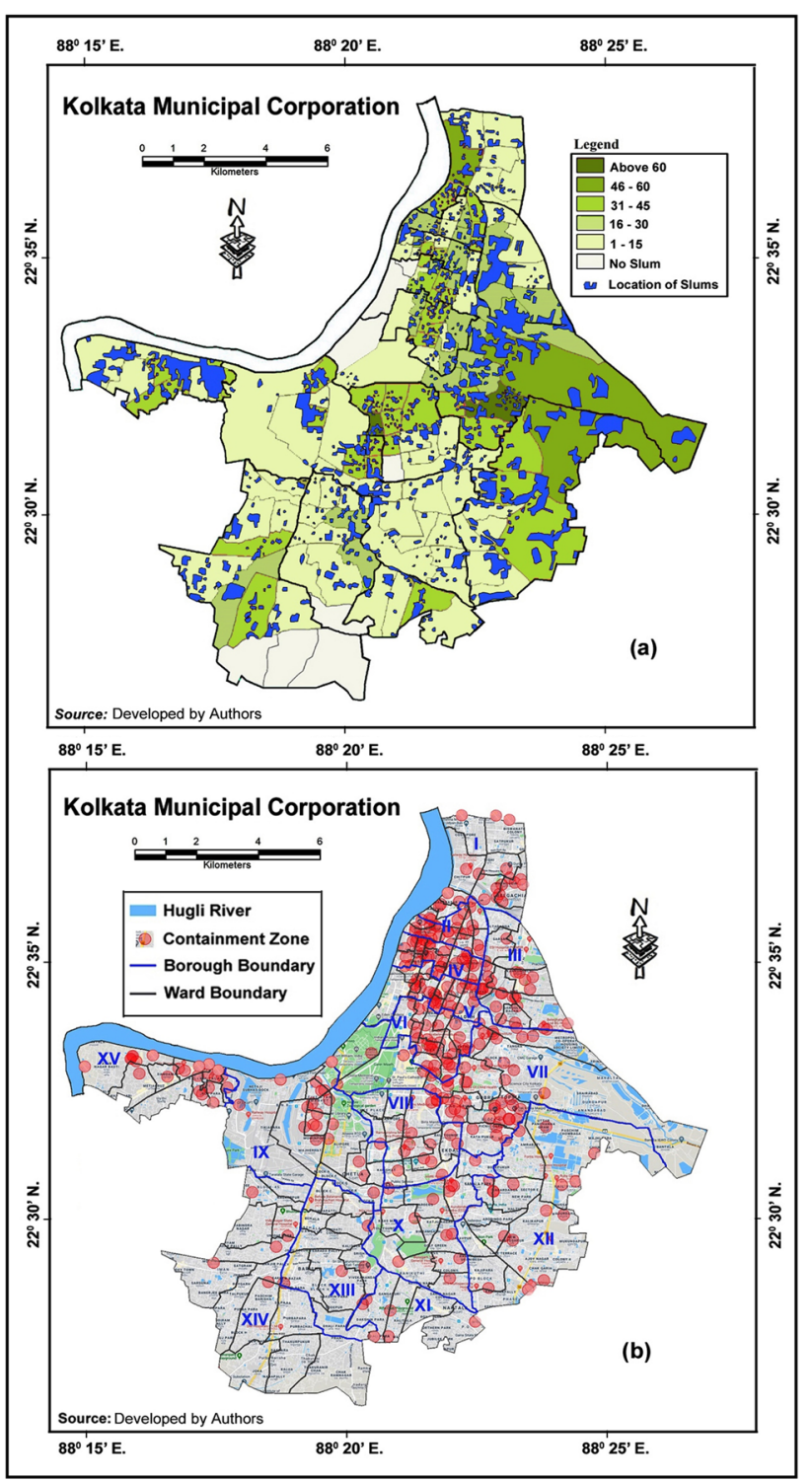

Fig. 6 Location of slums along with its number (a) and containment zones (on 12-05-2020) for SARS-CoV-2 confirmed cases in Kolkata Municipal Corporation

Old drainage system, located behind the rail lines and nullas (old sewerage lines) make the situation more worsen. Overall the area under Gardenreach, Metiaburuz (50\% of very high exposed wards from this area) with a high percentage of Muslim population face the higher degree of exposed of such infections (Fig. 8a). On the initial stage reluctant situation from Government end and non-maintaining the social distancing norm during nation-wide lockdown period make this areas face a terrible trouble and have experienced a number of SARS-CoV-2 cases with a large number of containment zones.

Sensitivity index analysis showing that of the total wards very high sensitivity has been found among 17 wards followed by 16 wards in high sensitive index, moderately

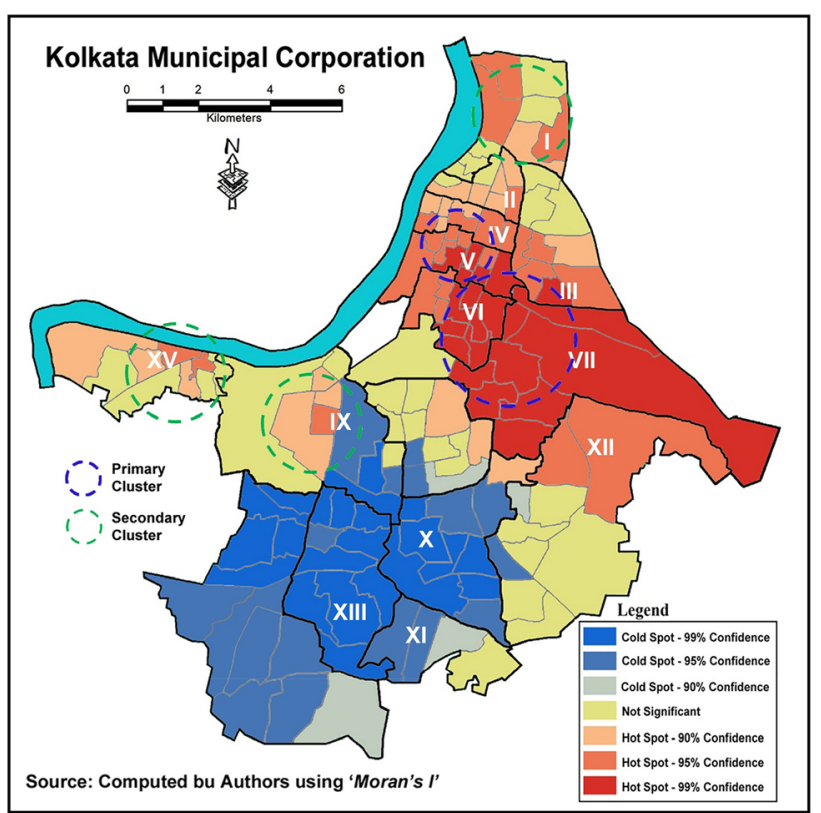

Fig. 7 Ward-wise distribution of containment zones due to SARSCoV-2 confirmed cases in Kolkata Municipal Corporation on hot spots of SARS-CoV-2

sensitivity found among 13 wards when 15 and 7 wards are found in low to very low sensitivity values respectively. High sensitive wards are mostly lies in the north Kolkata and partly in central Kolkata (Fig. 8b) where population density, household density, latrine and tube well dependency among the slum dwellers are very high which clearly gives the results of very high sensitive zones. These zones settled are much before of independence which has a migration legacy $(7,34)$.

Resilience capability among the selected wards of KMC found to be high as more than $64 \%$ of the total wards are characterised by very poor to moderate level of resilience. The wards are very much lagging behind in facilities which can protect them from such infections and the nature of infrastructural development are also found low in nature. Figure $8 \mathrm{c}$ shows that the most vulnerable wards (high to very high) located in central and eastern portion of the study area. Drinking water facilities, per-capita income and work participation rate are very low in these wards. Eastern portion wards of the study area are joined with KMC much later during 2000 onwards which shows the less unavailability of facilities in respect to others $(33,19)$.

Risk analysis revealed that very high vulnerability has been observed in 11 wards followed by high risk areas with 21 wards (nearly $30 \%$ to total wards under study). As a whole high to very high wards coved nearly $47 \%$ of the studied area (Fig. 8d) this indicates a disquieting situation for such infectious disease. Most of the wards located in central and some portion of north Kolkata. Four wards also 


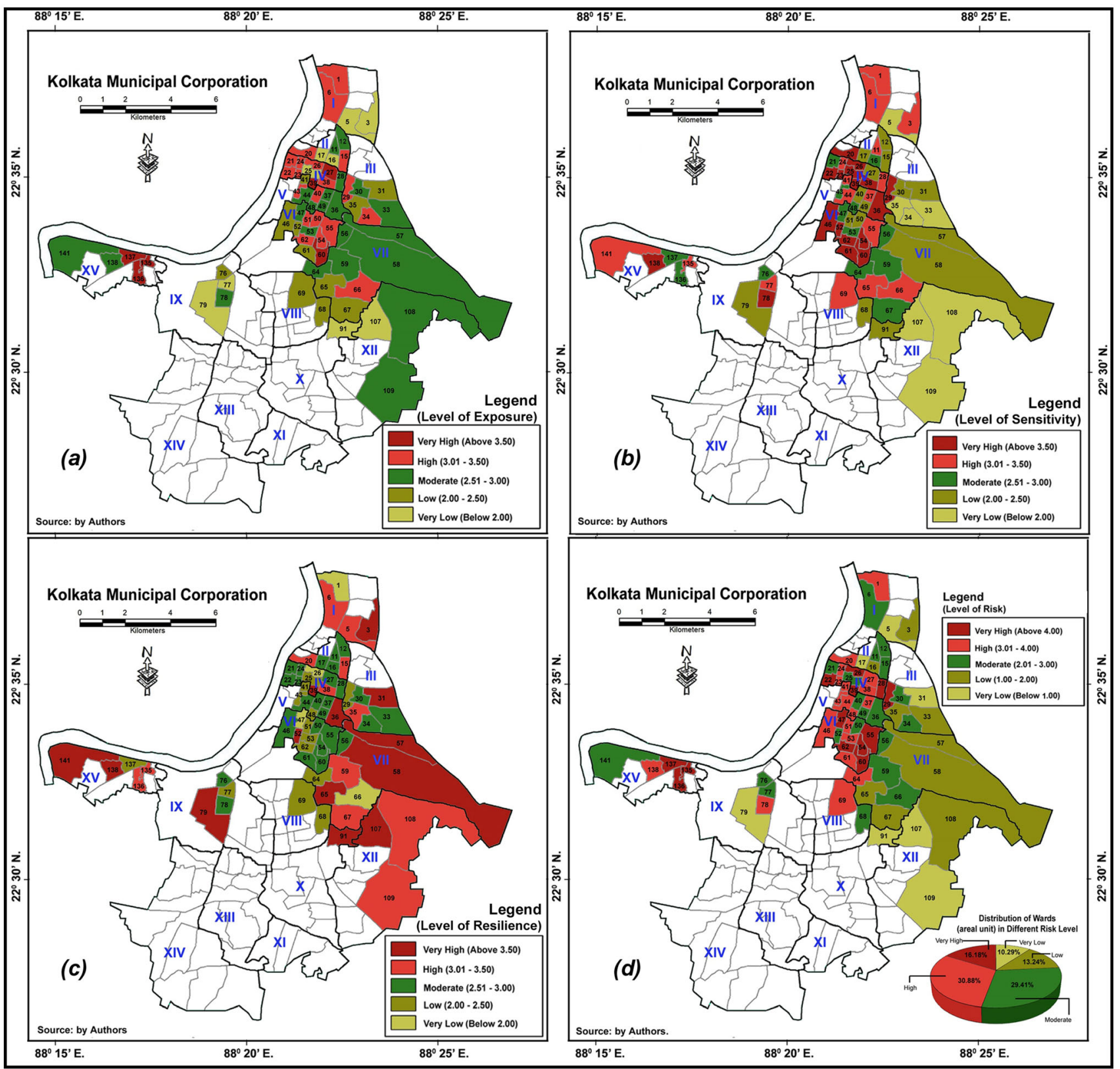

Fig. 8 Ward level (a) Exposure, (b) Sensitivity, (c) Resilience and (d) Risk to SARS-CoV-2 in the selected wards of Kolkata Municipal Corporation

found highly risk prone from extreme western portion of under Gandenreach-Metiaburuz area.

Most of the containment zones, high slum population share and density with excessive dependency on community toilet and tube well are the driving forces behind this high risk factor in these areas [34-36]. On the other hand low working population, low per-capita income, high household density in Topsia, Tiljala, Gardenreach, Rajabazar, Beliaghata, Burabazar, Jorabagan area make more hazard prone. Earlier evidences of dengue fever also found the same type of hotspots in the past years. Unhygienic and close spacing of settlements, not maintaining social distancing and very low per-capita space availability (nearly 5-7 persons in an 80-100 sq. feet room) make the region hotspots and rightly most of the SARS-CoV-2 cases found from these places. The spatiality of SARS-CoV-2 has wide-ranging expressively from April to May 2020, and it has exhibited consistency in northern and central part of KMC. A grouping of irregular and epidemic patterns of human-to-human exposure has been observed during this period [12]. By contrast, the distribution curve for cities in India, Mumbai has been experienced largest outbreak in 
India where Kolkata has constrains its spike. Purely temporal cluster analyses of SARS-CoV-2 infection illustrated significant clusters in April and May of 2020. This finding is consistent with previous studies of Eifan [34], which showed significant peaks in MERS-CoV incidence between March and May in Saudi Arabia in 2014. In this study, SARS-CoV-2 was observed during mass gatherings in different part of India, which are inconsistent with previous studies [35]. This indicates another knowledge gap regarding the mode of transmission that needs further investigation.

\section{Conclusion}

Though the transmission and outbreak has not a sudden one, major urban centres have been found more vulnerable to transmit this $\mathrm{H} 2 \mathrm{H}$ virus. High population density, concentration of high amount of slum population with high household density with low per-capita income shows the main driving factors for such outbreak. The people of those places are compel to break the said social distancing, as the people have a little, very little space for stay in household (in some cases they lived in 80 sq. feet area with 6-7 persons), they used to go and use community toilet, tube well sharing with other hundreds of population make the situation more grave $(3,8,9)$. Quick preparation and execution of the containment plan, deployment of adequate human resources (mainly from health workers) at ward level, active surveillance in the well-defined geographical area and higher test (Rapid Antibody Test) can minimise the chance of transmission in community level. As the spacing of households is very congested, such actions must be taken without any interference.

Acknowledgements The authors acknowledge the Department of Bustee Service, KMC, Hogg Buildings (3rd Floor), Kolkata for providing data support for the study.

Authors' contributions SP and SB designed the study; SH, AB and $\mathrm{BM}$ contributed to data acquisition; SK and SM carried out the statistical analysis; SP and SB drafted the manuscript. All authors contributed to the interpretation of data and revision of the manuscript. All authors read and approved the final manuscript.

Funding This work has not been supported by any State or Central Government funding agencies.

\section{References}

1. United Nations. (2018). Revision of world urbanization prospects. New York, NY: United Nations.

2. David, S. (2007). Urbanization and global environmental change: 21st century challenges. The Geographical Journal, 73(1), $75-92$.
3. Hui, D. S., Azhar, E. I., Kim, Y. J., Memish, Z. A., Oh, M. D., \& Zumla, A. (2018). Middle East respiratory syndrome coronavirus: Risk factors and determinants of primary, household, and nosocomial transmission. The Lancet Infectious Diseases, 18(8), 217-227. https://doi.org/10.1016/S1473-3099(18)30127-0.

4. Mberu, B. U., Haregu, T. N., Kyobutungi, C., \& Ezeh, A. C. (2016). Health and health-related indicators in slum, rural, and urban communities: A comparative analysis. Global Health Action, 9(33163), 1-14. https://doi.org/10.3402/gha.v9.33163.

5. Meng, B. U., Wang, J., Liu, J., Wu, J., \& Zhong, E. (2005). Understanding the spatial diffusion process of severe acute respiratory syndrome in Beijing. Public Health, 119(12), 1080-1087. https://doi.org/10.1016/j.puhe.2005.02.003.

6. Census of India. Primary Census Abstract. (2011). Abstract for slums. Office of the Registrar General and Census Commissioner: New Delhi. Retrieved 12 May, 2020, from http://www.cen susindia.gov.in/2011-Documents/Slum-26-09-13.pdf.

7. Ghosh, S. (2013). Regional disparities of slums, 2013-An overview with special emphasis to Kolkata. International Journal of Humanities and Social Science Invention, 2, 48-54. https://doi. org/10.13140/RG.2.2.29748.96641.

8. Dayun, K., Huynh, C., Jong, H. K., \& Jungsoon, C. (2020). Spatial epidemic dynamics of the COVID-19 outbreak in China. International Journal of Infectious Diseases, 94, 96-102. https:// doi.org/10.1016/j.ijid.2020.03.076.

9. Kraemer, M. U. G., Faria, N. R., Reiner, R. C., Golding, N., Nikolay, B., Stasse, S., et al. (2017). Spread of yellow fever virus outbreak in Angola and the Democratic Republic of the Congo 2015-16: A modelling study. The Lancet Infectious Diseases, 17, 330-338. https://doi.org/10.1016/S1473-3099(16)30513-8.

10. WHO. (2020). Modes of transmission of virus causing COVID19: Implications for IPC precaution recommendations. Retrieved April 24, 2020, from file:/20200329-scientific-brief1-final-corrected2-revised-final.pdf.

11. Chen, T. M., Jia, R., Wang, Q. P., Zhao, Z., Cui, J. A., \& Yin, L. (2020). A mathematical model for simulating the phase-based transmissibility of a novel coronavirus. Infectious Diseases of Poverty, 9(24), 1-8. https://doi.org/10.1186/s40249-020-00640-3.

12. Al-Ahmadi, K., Alhmadi, S., \& Al-Zahrani, A. (2019). Spatiotemporal clustering of Middle East respiratory syndrome coronavirus (MERS-CoV) incidence in Saudi Arabia, 2012-2019. International Journal of Environmental Research and Public Health, 16(14), 2520. https://doi.org/10.3390/ijerph16142520.

13. Fournet, F., Rican, S., Vaillant, Z., Roudot, A., Meunier, N. A., Kassié, D., et al. (2020). The influence of urbanization modes on the spatial circulation of flaviviruses within Ouagadougou (Burkina Faso). International Journal of Environmental Research and Public Health, 13, 1226. https://doi.org/10.3390/ ijerph13121226.

14. Kraemer, M. U. G., Faria, N. R., Reiner, R. C., Golding, N., Nikolay, B., Stasse, S., et al. (2017). Spread of yellow fever virus outbreak in Angola and the Democratic Republic of the Congo 2015-16: A modelling study. The Lancet Infectious Diseases, 2017(17), 330-338. https://doi.org/10.1016/S14733099(16)30513-8.

15. Magalhaes, R. J. S., Langa, A., Sousa, F. J. C., Clements, A. C., \& Nery, S. V. (2012). Finding malaria hot-spots in northern Angola: The role of individual, household and environmental factors within a meso-endemic area. Malaria Journal, 11, 385. https://doi.org/10.1186/1475-2875-11-385.

16. Li, H., Calder, C. A., \& Cressie, N. (2007). Beyond Moran's I: Testing for spatial dependence based on the spatial autoregressive model. Geographical Analysis, 39(4), 357-375. https://doi.org/ 10.1111/j.1538-4632.2007.00708.x.

17. Bhunia, G. S., Siddiqui, N. A., Shit, P. K., Chatterjee, N., \& Sinha, S. K. (2016). Spatial clustering of Plasmodium falciparum 
in Bihar (India) from 2007 to 2015. Spatial Information Research, 24(6), 639-648. https://doi.org/10.1007/s41324-0160061-7.

18. Wang, S. J., Lengeler, C., Smith, T. A., Vounatsou, P., Diadie, D. A., Pritroipa, X., et al. (2005). Rapid urban malaria appraisal (RUMA): Epidemiology of urban malaria in Ouagadougou. Malaria Journal, 4, 43. https://doi.org/10.1186/1475-2875-4-43.

19. Srivastava, A., Nagpal, B. N., Joshi, P. L., Paliwal, J. C., \& Dash, A. P. (2009). Identification of malaria hot spots for focused intervention in tribal state of India: A GIS based approach. International Journal of Health Geographics, 8, 1-8.

20. Saaty, T. L. (1980). The analytic hierarchy process: Planning, priority setting, resources allocation. New York: McGraw Hill.

21. Fernandez, D. F., \& Lutz, M. A. (2010). Urban flood hazard zoning in Tucuman Province Argentina using GIS and multicriteria decision analysis. Engineering Geology, 111, 90-98. https:// doi.org/10.1016/j.enggeo.2009.12.006.

22. IPCC. (2014). Summary for policymakers. In C. B. Field, V. R. Barros, D. J. Dokken, K. J. Mach, M. D. Mastrandrea, T. E. Bilir, et al. (Eds.) Climate change 2014: Impacts, adaptation, and vulnerability. Part A: Global and sectoral aspects. Contribution of Working Group II to the fifth assessment report of the intergovernmental panel on climate change (pp. 1-32). Cambridge: Cambridge University Press.

23. MOHFW. (2020). Containment plan for large outbreaks. Retrieved May 17, 2020, from https://www.mohfw.gov.in/pdf/ ContainmentPlanforLargeOutbreaksofCOVID19Final.pdf.

24. Aydın, S., \& Uysal, S. (2014). Risk assessment of coastal erosion of Karasu coast in Black Sea. Journal of Coastal Conservation, 2014(18), 673-682. https://doi.org/10.1007/s11852-014-0343.

25. http://www.covid19india.org.

26. https://www.covidhotspot.in/.
27. https://timesofindia.indiatimes.com/india/13-urban-sprawlsaccount-for-2/3rd-of-indias-cases-deaths/articleshow/75524643. cms.

28. http://www.howindialives.com/gram/coronadistricts.

29. https://www.moneycontrol.com/news/trends/coronavirus-pan demic-2600-covid-19-cases-traced-back-to-vegetable-market-inchennai-5266211.html.

30. http://www.wesearchlab.com/kolkatacoronavirus/.

31. KMDA. (2016). An impact evaluation study of BSUP Programme Intervention in Kolkata Metropolitan Area (KMA), Kolkata Municipal Development Authority.

32. https://www.deccanherald.com/national/west/surge-in-covid-19cases-in-gujarat-linked-to-tablighi-jamaat-meet-821830.html.

33. Mukherjee, S., Sundberg, T., \& Schutt, B. (2020). Assessment of water security in socially excluded areas in Kolkata, India: An approach focusing on water, sanitation and hygiene. Water, 12, 1-36. https://doi.org/10.3390/w12030746.

34. Eifan, S. A., Nour, I., Hanif, A., Zamzam, A. M. M., \& AlJohani, S. M. (2017). A pandemic risk assessment of middle-east respiratory syndrome Coronavirus (MERS-CoV) in Saudi Arabia. Saudi Journal of Biological Sciences, 24, 1631-1638.

35. Al-Tawfiq, J. A., Benkouiten, S., \& Memish, Z. A. (2017). A systematic review of emerging respiratory viruses at the Hajj and possible coinfection with Streptococcus pneumoniae. Travel Medicine and Infectious Disease, 23, 6-13.

36. Bose, R., \& Ghosh, S. (2015). Slums in Kolkata: A socio-economic analysis. The Empirical Econometrics and Quantitative Economics Letters, 3(3), 134-148.

Publisher's Note Springer Nature remains neutral with regard to jurisdictional claims in published maps and institutional affiliations. 